\title{
THE INHIBITION OF STEEL CORROSION IN ACIDIC SOLUTIONS BY A NEW SCHIFF BASE
}

\author{
N. K. BAKIRHAN $N^{a, b^{*}}, A . A S A N^{c}$, N. COLAK ${ }^{b}, S . S A N L I^{d}$ \\ ${ }^{a}$ Department of Analytical Chemistry, Faculty of Pharmacy, Ankara University, 06100 Ankara, Turkey \\ ${ }^{b}$ Hitit University, Science \& Literature Faculty, Department of Chemistry, 19100, Corum, Turkey \\ 'Hitit University, Engineering Faculty, Department of Chemical Engineering, 19030, Çorum, Turkey \\ ${ }^{d}$ Usak University, Science\&Arts Faculty, Department of Chemistry, Usak, 64200, Turkey
}

\section{ABSTRACT}

The inhibition effect of 2,2'- (((thiobis (4,1 phenylene)) bis(azanylylidene)) bis(methanylyidene)) bis(4-methoxyphenol) (BIS-IMIN) on the corrosion behavior of 304-stainless steel (SS) in $0.5 \mathrm{M} \mathrm{HCl}$ solution was studied by electrochemical impedance spectroscopy (EIS) and potentiodynamic polarization techniques. SEM, FT-IR, ${ }^{1} \mathrm{H}$-NMR, ${ }^{13} \mathrm{C}-\mathrm{NMR}$ methods used for characterization of BIS-IMIN. Potentiodynamic polarization curves indicated that BIS-IMIN act as mixed type inhibitor. The adsorption of the inhibitor was more suited with the Langmuir adsorption isotherm and kinetic parameters $K_{\text {ads }}, \Delta G_{\text {ads, }} E_{\text {a }}, \Delta H_{\text {ads, }}, \Delta S_{\text {ads }}$ were determined at room temperature. The results showed that BIS-IMIN performed well inhibiting effect for the corrosion of the SS.

Keywords: Corrosion inhibitors; Stainless steel; potentiodynamic polarization; Electrochemical impedance spectroscopy.

\section{INTRODUCTION}

Nowadays, steel has been currently used as important construction materials in industry [1]. The inhibition of steel in acidic mediums by different types of organic inhibitors has been extensively studied. The use of these inhibitors is one of the most practical methods for protecting against the corrosion and its popularity is increasing. The heterocyclic organic compounds which have especially electroactive groups (sulfur, oxygen, nitrogen) have excellent properties for inhibition of corrosion of steel in acidic medias [2-5].

Corrosion inhibition of organic compounds depend on adsorption mechanism on the metal surface. That adsorption mechanism occurs by following steps;

a) Electrostatic interaction between charged metal surface and charged inhibitor structure,

b) The interaction of unshared electron pairs of organic compounds with charged metal surface,

c) The interaction of $\pi$-electron with metal surface,

d) The combination of the (a-c) above steps [6, 7].

In this research, our aim is to investigation of the inhibition effect of BIS-IMIN on the corrosion behavior of SS in $0.5 \mathrm{M} \mathrm{HCl}$ solution and clarify its inhibition mechanism using Tafel polarization, electrochemical impedance spectroscopy. In addition to electrochemical studies, characterization of inhibited molecule was determined by SEM, FT-IR, ${ }^{1} \mathrm{H}-\mathrm{NMR}$ and ${ }^{13} \mathrm{C}-\mathrm{NMR}$ spectrums

\section{EXPERIMENTAL}

4-(4-Aminophenylthio)benzenamine $(1.08 \mathrm{~g}, 5 \mathrm{mmol})$ solution in ethanol $(20 \mathrm{~mL}), 2$-hydroxy-5-methoxybenzaldehyde $(1.52 \mathrm{~g}, 10 \mathrm{mmol})$ in ethanol (30 $\mathrm{mL}$ ) was added drop by drop, the solution was stirred for $3 \mathrm{~h}$ at $25^{\circ} \mathrm{C}$. The obtained precipitate was filtered and dried under the vacuum. The solution was filtered warmly to remove impurities, and then left for crystallization at 25 ${ }^{\circ} \mathrm{C}$. Yield: $1.97 \mathrm{~g}(81 \%)$, melting point: $197-199^{\circ} \mathrm{C}$. $\mathrm{C}_{28} \mathrm{H}_{24} \mathrm{~N}_{2} \mathrm{~S}(484.15)$ Calc. C 69.40, H 4.99, N 5.78, O 13.21, S 6.62; found: $69.27^{24}$, H 5.21, N 5.63, $\mathrm{S}$ 6.48. The chemical structure of the investigated compound is represented in Figure 1.

The immersed time and temperature effects $(298-328 \mathrm{~K})$ were investigated of the BIS-IMIN compound towards the corrosion of SS at $0.5 \mathrm{M} \mathrm{HCl}$ solution with or without inhibitors.

All solutions were prepared from analytical-grade chemicals and doubly distilled water. The chemical composition of working electrode SS: $18.18 \%$ $\mathrm{Cr}, 8.48 \% \mathrm{Ni}, 2 \% \mathrm{Mn}, 0.75 \% \mathrm{Si}, 0.1 \% \mathrm{~N}, 0.08 \% \mathrm{C}, 0.045 \% \mathrm{P}, 0.03 \% \mathrm{~S}$ and remainder is Fe. SS was embedded in epoxy resin and its geometrical surface area is $1 \mathrm{~cm}^{2}$. SS cleaning procedure was performed by polishing with a series of emery papers up to 1200 grad, washed with acetone and distilled water to removing of unpurities. Than SS was immersed in test solution without and with known concentration of BIS-IMIN. The concentration effect of inhibitor was studied between $5.0 \times 10^{-3} \mathrm{M}$ to $5.0 \times 10^{-5} \mathrm{M}$.

For electrochemical measurements, a three-electrode electrochemical cell was used. SS as working electrode, platinium as counter electrode and saturated calomel electrode (SCE) as a reference electrode were put in electrochemical cell. CHI 660B electrochemical analyzer was used for measurements. EIS measurements obtained at $10^{5}$ to $10^{-2} \mathrm{~Hz}$ frequency range and $7 \mathrm{mV}$ amplitude. All electrochemical experiments were performed without stirring at $25{ }^{\circ} \mathrm{C}$. During the polarization measurement, the potential scan rate was used as 1.0
$\mathrm{mVs}^{-1}$.

The ${ }^{1} \mathrm{H}$ and ${ }^{13} \mathrm{C}$ NMR spectra were performed on a Bruker AVANCE DPX NMR spectrometer operating at 400 and $101.6 \mathrm{MHz}$. The ${ }^{1} \mathrm{H}$ and ${ }^{13} \mathrm{C}$ NMR chemical shifts were measured using $\mathrm{SiMe}$ as an internal standard. Infrared absorption spectra were obtained from a Nicolet 6700 spectrometer in ATR and were reported in $\mathrm{cm}^{-1}$ units. Carbon, nitrogen and hydrogen analyses were performed on a LECO CHNS-932 analyzer. Melting points were measured on an Electro Thermal IA 9100 apparatus using a capillary tube.

Surface morphologies of electrodes and investigation of elemental analysis of surface were obtained by SEM coupled with an EDS detector and LEO 440 microscope.

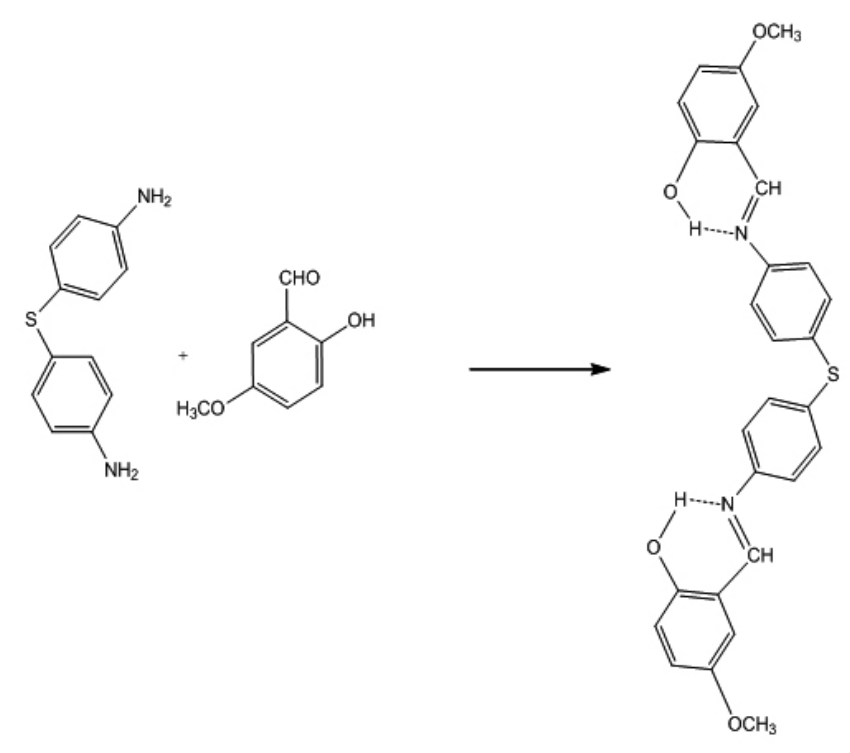

Fig. 1. The synthesis of BIS-IMIN molecule.

\section{RESULTS AND DISCUSSION}

\subsection{Effect of inbitior concentration}

3.1.1. EIS

To investigate the effects of the inhibitor concentration on the impedance behavior of SS in acid solution have been studied. Nyquist diagrams are given in Fig. 2.

It is clear from these Figures that the impedance spectra obtained yields a semi circular shape. This shows the corrosion of the $\mathrm{SS}$ in $0.5 \mathrm{M} \mathrm{HCl}$ solution is mainly controlled by a charge transfer process $[8,9]$. The charge transfer resistance $(R)$ must be corresponding to the resistance between the metal and OHP (Outer Helmholtz Plane) [10]. $R$ is calculated from the difference of lower and higher frequencies [11]. The double-layer capacitance $\left(C_{\mathrm{b}}\right)$ is obtained from the maximum frequency at imaginary component of the impedance [12]: 


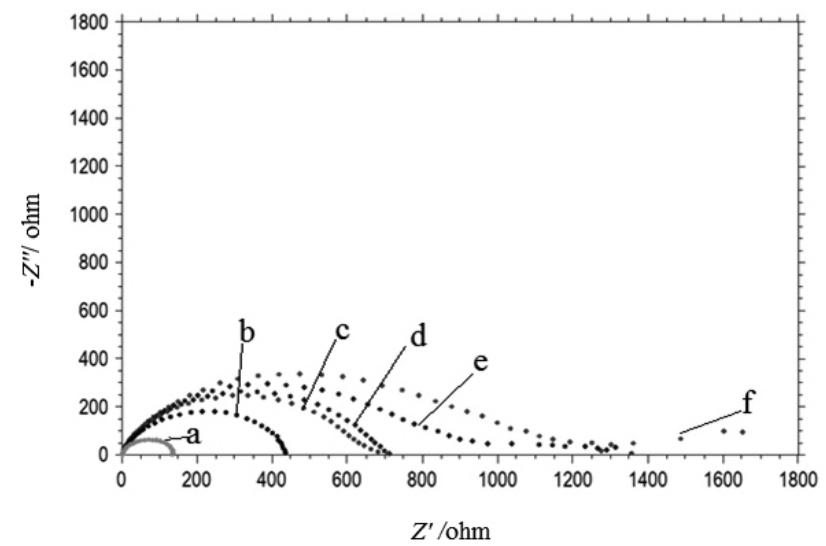

Fig. 2. Nyquist plots for $\mathrm{SS}$ in $0.5 \mathrm{M} \mathrm{HCl}$ solution in the absence (a) and presence of $5 \times 10^{-5} \mathrm{M}(\mathrm{b}), 1 \times 10^{-4} \mathrm{M}(\mathrm{c}), 5 \times 10^{-4} \mathrm{M}(\mathrm{d}), 1 \times 10^{-3} \mathrm{M}(\mathrm{e}), 5 \times 10^{-3} \mathrm{M}$ (f) inhibitor at $298 \mathrm{~K}$.

$$
C_{\mathrm{dl}}=1 /\left(2 \Pi f_{\text {max }} R_{c t}\right)
$$

Table.1. Impedance data of SS in $0.5 \mathrm{M} \mathrm{HCl}$ without and with addition of $5.0 \times 10^{-3} \mathrm{M}$ of inhibitors at $298 \mathrm{~K}$.

\begin{tabular}{lccccc}
\hline Inhibitor & $\boldsymbol{C}_{\text {inh }}(\boldsymbol{M})$ & $\boldsymbol{R}_{\mathrm{p}}(\boldsymbol{\Omega})$ & $\boldsymbol{C}_{\mathrm{dl}}\left(\boldsymbol{\mu} \boldsymbol{F} \boldsymbol{c m}^{-2}\right)$ & $\boldsymbol{I E}(\%)$ & $\boldsymbol{\theta}$ \\
\hline Blank & - & 142.2 & 114.7 & - & - \\
$\underline{\text { Inhibitor }}$ & $5.0 \times 10^{-5}$ & 444.3 & 26.63 & 68.0 & 0.680 \\
& $1.0 \times 10^{-4}$ & 680.9 & 14.52 & 79.1 & 0.791 \\
& $5.0 \times 10^{-4}$ & 722.1 & 14.40 & 80.3 & 0.803 \\
& $1.0 \times 10^{-3}$ & 970.5 & 11.03 & 85.3 & 0.853 \\
& $5.0 \times 10^{-3}$ & 1300 & 8.517 & 89.1 & 0.891 \\
\hline
\end{tabular}

The impedance results are given in Table 1. According to the results, the protection of SS surface from the corrosive media is succesfull with BIS-IMIN. In the electrochemical impedance spectroscopy, the inhibition efficiency $(I E)$ is calculated using $R_{c t}$ as follows:

$$
\% I E=\left(R_{c t \text { (inh) }}-R_{c t}\right) / R_{c t(\text { inh })} \times 100
$$

In the equation 2, $R_{\text {t }}$ and $R_{\text {cttinh }}$ are the charge transfer resistance values without and with BIS-IMIN in $0.5 \mathrm{M} \mathrm{HCl}$, respectively. With BIS-IMIN concentration, the $R$ values increased, while the $C_{\text {d }}$ values were decreased. Decreasing $C_{\mathrm{dl}}$ values are related to replacement of water molecules with organic molecules which are adsorbed on the SS surface, so that metal dissolution is blocked [13,14]. As know that nitrogen atom in molecule can be easily protonated in acidic solutions [15]. This protonated nitrogen atom adsorbs on the positively charged iron surface in acidic media and then the anodic dissolution of iron follows these steps:

$$
\begin{aligned}
& \mathrm{Fe}+\mathrm{Cl}^{-} \leftrightarrow\left(\mathrm{FeCl}^{-}\right)_{\text {ads }} \\
& (\mathrm{FeCl}-)_{\text {ads }} \leftrightarrow(\mathrm{FeCl})_{\text {ads }}+\mathrm{e}^{-} \\
& \left(\mathrm{FeCl}{ }_{\text {ads }}\left(\mathrm{FeCl}^{+}\right)+\mathrm{e}^{-}\right. \\
& \mathrm{FeCl}^{+} \leftrightarrow \mathrm{Fe}^{2+}+\mathrm{Cl}^{-}
\end{aligned}
$$

The cathodic hydrogen evolution follows the steps:

$$
\begin{aligned}
& \mathrm{Fe}+\mathrm{H}^{+} \leftrightarrow\left(\mathrm{FeH}^{+}\right)_{\text {ads }} \\
& (\mathrm{FeH})_{\text {ads }}+\mathrm{e}^{-} \rightarrow(\mathrm{FeH})_{\text {ads }} \\
& (\mathrm{FeH})_{\text {ads }}+\mathrm{H}^{+}+\mathrm{e}^{-} \rightarrow \mathrm{Fe}+\mathrm{H}_{2}
\end{aligned}
$$

Electron donating groups on the molecules effect the electron density of structure such as $\mathrm{S}$ with donating groups increases the electron density on the nitrogen of the $-\mathrm{C}=\mathrm{N}-$ group, resulting high inhibition efficiency [16].

\subsubsection{Potentiodynamic polarization measurements}

Polarization measurements have been studied to obtaine knowledge about the kinetics of the anodic and cathodic reactions. After $15 \mathrm{~min}$ of immersing the steel electrode in $0.5 \mathrm{M} \mathrm{HCl}$ solution without and with different concentrations BIS-IMIN, measurements have been carried out in the potential range $\left(E_{ \pm} \pm\right.$ $200 \mathrm{mV}$ ) at a scan rate of $1.0 \mathrm{mVs}^{-1}$. The inhibition efficiency, $I E \%$, at different BIS-IMIN concentrations was calculated from the polarization measurements using the Equation 3. [17], respectively.

$$
\% I E=\left(I_{\mathrm{o}}-I_{\mathrm{i}}\right) / I_{\mathrm{o}} \times 100
$$

where $I$ and $I$ are the corrosion current densities for steel electrode in the uninhibited and inhibited solutions, respectively.
Fig. 3 shows the effect of BIS-IMIN concentration on the cathodic and the anodic polarization curves of steel in $0.5 \mathrm{M} \mathrm{HCl}$. The polarization parameters calculated from these curves are illustrated in Table 2. Fig. 3 shows that increasing the BIS-IMIN concentration reduces both the cathodic and the anodic currents with a slight cathodic shift in the $E$ values.

According to the decreasing of concentration values and cathodic-anodic densities of BIS-IMIN, were decreased and this showed us BIS-IMIN is a mixed-type inhibitor. In the other way, addition of BIS-IMIN reduces anodic dissolution and cathodic hydrogen evolution reaction.

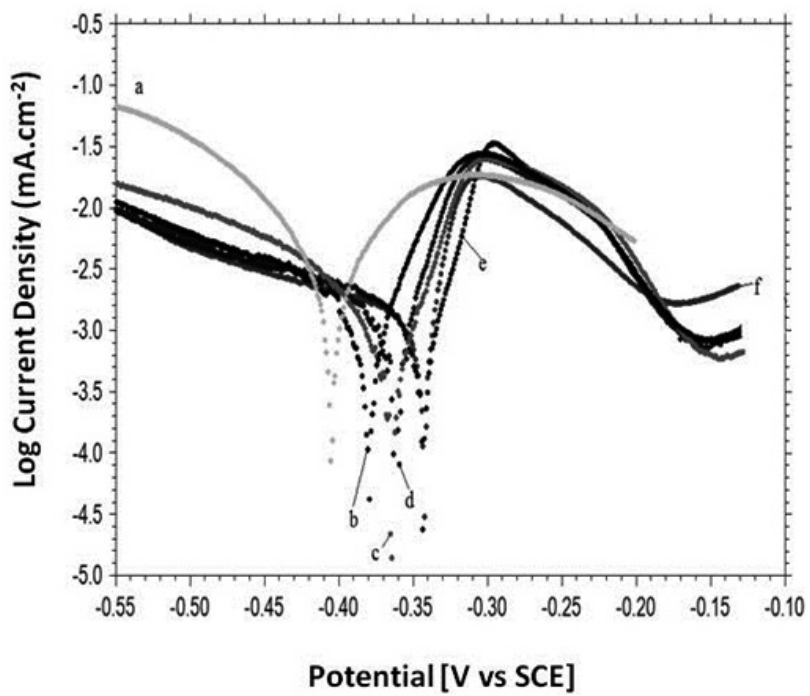

Fig. 3. Effect of inhibitor concentration on the potentiodynamic polarization response for $\mathrm{SS}$ in $0.5 \mathrm{M} \mathrm{HCl}$ solution in the absence (a) and presence of $5 \times 10^{-5} \mathrm{M}(\mathrm{b}), 1 \times 10^{-4} \mathrm{M}(\mathrm{c}), 5 \times 10^{-4} \mathrm{M}(\mathrm{d}), 1 \times 10^{-3} \mathrm{M}(\mathrm{e}), 5 \times 10^{-3} \mathrm{M}$ (f) inhibitor at $298 \mathrm{~K}$.

Table.2. Polarization parameters of steel corrosion in $0.5 \mathrm{M} \mathrm{HCl}$ without and with addition of various concentrations of inhibitor.

\begin{tabular}{lccccc}
\hline Inhibitor & $\boldsymbol{C}_{\text {inh }}(\boldsymbol{M})$ & $\boldsymbol{E}_{\text {corr }} \boldsymbol{v S} \boldsymbol{S C E}(\boldsymbol{V})$ & $\boldsymbol{I}_{\text {corr }}\left(\boldsymbol{m} \boldsymbol{A} \mathbf{c m}^{-2}\right)$ & $\boldsymbol{I} \boldsymbol{E} \%$ & $\boldsymbol{\theta}$ \\
\hline$\underline{\text { Blank }}$ & - & -0.405 & 16.7 & - & - \\
$\underline{\underline{\text { Inhibitor }}}$ & $5.0 \times 10^{-5}$ & -0.379 & 5.01 & 69.9 & 0.699 \\
& $1.0 \times 10^{-4}$ & -0.363 & 3.34 & 80.1 & 0.801 \\
& $5.0 \times 10^{-4}$ & -0.360 & 2.51 & 84.9 & 0.849 \\
& $1.0 \times 10^{-3}$ & -0.343 & 2.34 & 86.0 & 0.860 \\
& $5.0 \times 10^{-3}$ & -0.342 & 1.66 & 90.1 & 0.901 \\
\hline
\end{tabular}

\subsection{Adsorption isotherm}

Chemical stuctures of organic molecules affect the adsorption process [18]. Temkin, Langmuir, Flory-Huggins, Bockris-Swinkels and Frumkin adsorption isotherms are studied and checked to find the best suitable isotherm for adsorption of BIS-IMIN molecule on the steel surface in the acid solution. Langmuir adsorption isotherm, which is given by Eq. (4) was found more suitable with an average correlation coefficient of 0.9999 (Fig. 4).

$$
C / \theta=1 / K_{\text {ads }}+C
$$

where $C$ is inhibitor concentration, $\theta$ is the degree of the coverage on the metal surface and $K$ is the equilibrium constant for the adsorptiondesorption process [18]. The value of equilibrium constant, $K$ calculated from the reciprocal of the intercept of isotherm line as $33.6 \mathrm{M}^{-1}$. The high value of the adsorption equilibrium constant reflects the high adsorption ability of this BIS-IMIN on SS surface. The free energy of the adsorption of inhibitor on SS surface can be evaluated with the following equation;

$$
\Delta G_{\text {ads }}=-R T \ln \left(55.5 K_{\text {ads }}\right)
$$

where $R$ is the gas constant and $T$ is the absolute temperature. The constant value of 55.5 is the concentration of water in solution in $\mathrm{mol} / \mathrm{dm}^{3}$. From Eq. (5), $\Delta G$ was calculated as $-18.66 \mathrm{kJmol}^{-1}$. The negative value of $\Delta G$ means spontaneous adsorption of the BIS-IMIN on the SS surface [19] and adso the strong interaction between BIS-IMIN molecules and SS [20]. The value of $\Delta G_{\text {ads }}$ is less than $40 \mathrm{~kJ} \mathrm{~mol}^{-1}$ is commonly interpreted with the presence of physical adsorption by the formation of an adsorptive film with an electrostatic character $[21,22]$. 


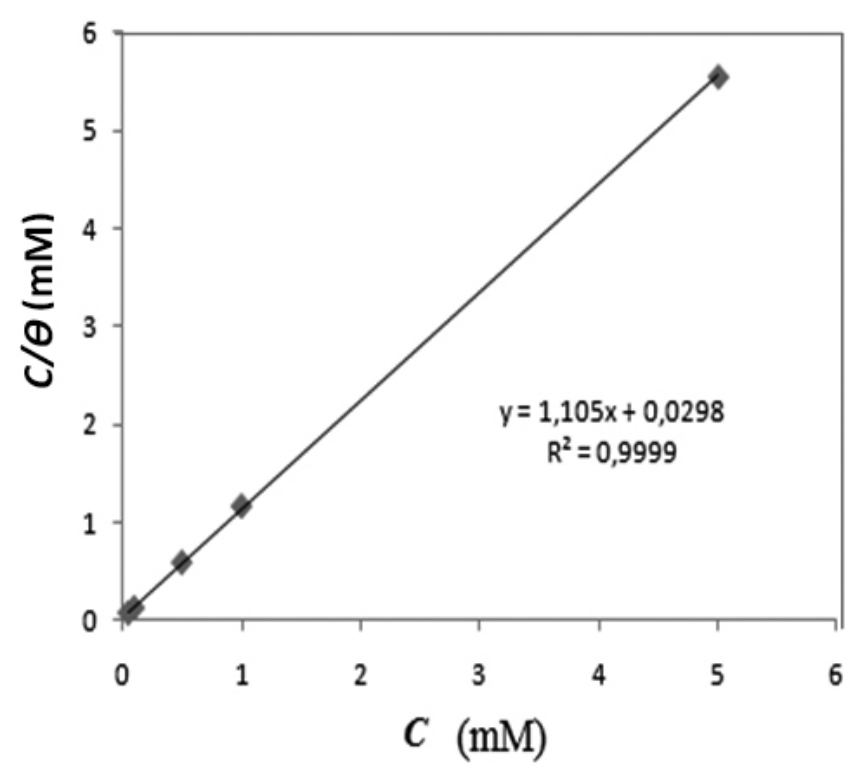

Fig. 4. Langmuir isotherm for the SS electrode in $0.5 \mathrm{M} \mathrm{HCl}$ containing different concentrations of BIS-IMIN.

In physisorption process, it can be assumed that acid anions such as $\mathrm{Cl}^{-}$ ions are adsorbed on the metal surface, donating an excess negative charge to the metal surface. In this way, cationic inhibitor molecule adsorbed on the negatively charged surface. This is also shown by other researchers [23, 24].

\subsection{Effect of temperature}

The effect of temperature on the inhibited acid-metal reaction is very complex, because many changes occur on the metal surface such as rapid etching and desorption of inhibitor and the inhibitor itself may undergo decomposition [25]. The change of the corrosion rate with the temperature was investigated in $0.5 \mathrm{M} \mathrm{HCl}$, both in absence and presence of BIS-IMIN. Potantiodynamic polarization measurements were performed at different temperatures from 25 to $55^{\circ} \mathrm{C}$ in absence (Fig. 5) and presence of $5 \times 10^{-3} \mathrm{M}$ of BIS-IMIN. (Fig. 6).

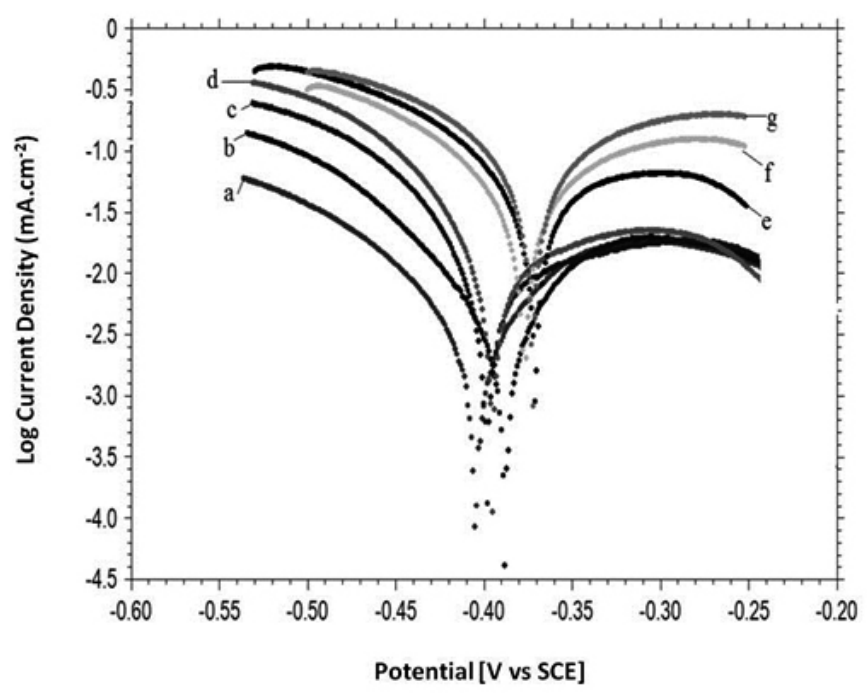

Fig. 5. Anodic and cathodic polarization curves for $\mathrm{SS}$ in $0.5 \mathrm{M} \mathrm{HCl}$ without inhibitor at different temperatures.

By the Arrhenius equation, the apparent activation energy $(E)$ of metal corrosion in both media (blank and inhibited) can be calculated from the following equation $[26]$ :

$$
\ln I_{\text {corr }}=\ln A-E_{\mathrm{a}} / R \cdot T
$$

where $\mathrm{A}$ is the Arrhenius constant.

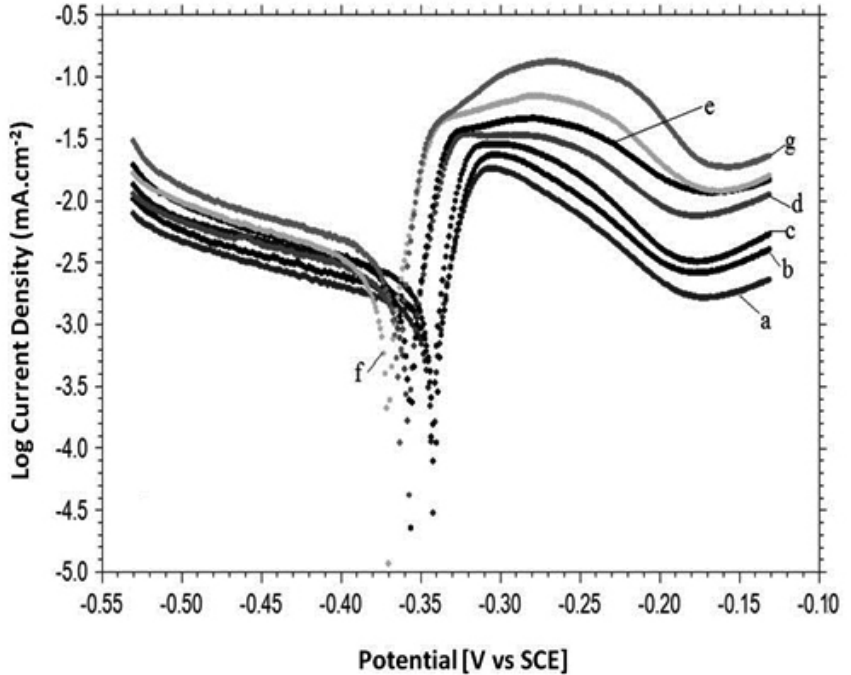

Fig. 6. Anodic and cathodic polarization curves for SS in $0.5 \mathrm{M} \mathrm{HCl}$ with $5 \times 10^{-3} \mathrm{M}$ of BIS-IMIN at different temperatures.

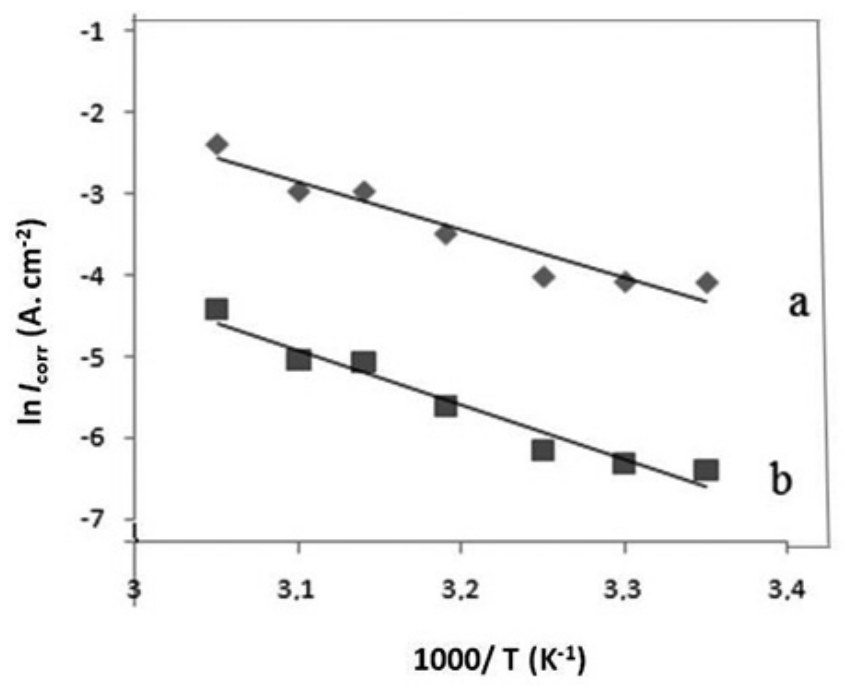

Fig. 7. $\ln i_{\text {corr }}$ vs $1000 / T$ for SS dissolution in $0.5 \mathrm{M} \mathrm{HCl}$ in the absence (a) and presence (b) $5 \times 10^{-3} \mathrm{M}$ of BIS-IMIN

Fig. 7 shows the logarithm of $i_{\text {corr }}$ against the reciprocal of temperature in the absence and presence of BIS-IMIN. The $E_{\mathrm{a}}$ values of reactions on the electrode surfaces are calculated from the slope of lines at $\ln I$ versus $1000 / T\left(K^{-1}\right)$. The calculated value of $E$ in the absence of inhibitor is $49.40 \mathrm{~kJ} /$ $\mathrm{mol}$, while in the presence of BIS-IMIN is $56.11 \mathrm{~kJ} / \mathrm{mol}$ respectively. In the literatures, the higher $E_{\mathrm{a}}$ for corrosion process in the presence of an inhibitor is attributed to the physisorption of inhibitör [13].

The heat of adsorption process $\left(Q_{\text {af }}\right)$ can be calculated from the variation of surface coverage versus reciprocal of temperature by using the Langmuir's adsorption isotherm as following [27]:

$\log [\theta / 1-\theta]=\log A+\log C-Q / 2.3 R T$

where $A$ is a constant and $Q_{\text {de }}$ is the heat of adsorption and equal to enthalpy of adsorption process $\left(\Delta H_{\text {ads }}^{\text {ds }}\right)$ with good approximation.

Fig. 8 represents the variation of $\log [\theta /(1-\theta)]$ versus $1 / T$ for inhibitor molecule. The heat of adsorption can be found from the slope of the lines, which are equal to $\left(-Q_{\mathrm{ads}} / 2.303 R\right)$. The entropy of adsorption process $\left(\Delta S^{o}{ }_{\mathrm{ads}}\right)$ can be calculated based on the following thermodynamic basic equation [28]:

$$
\Delta G_{\text {ads }}=\Delta H_{\text {ads }}-T \Delta S_{\text {ads }}
$$

The heat of adsorption $(Q)$ and the entropy value of the inhibitor adsorption $(\Delta S)$ were calculated as $-7.51 \mathrm{kJmol}^{-1}$ and $37.4 \mathrm{Jmol}^{-1} \mathrm{~K}^{-1}$, respectively. The negative $\Delta$ Hads value means that the exothermic reaction is 
occurred in solution between the SS suface and corrosive media. this reaction is explained as inhibitor compound adsorbs on metal surface and at the same time water molecule desorbs from the metal surface [29]:

$$
\mathrm{Org}_{\text {(sol) }}+\mathrm{xH}_{2} \mathrm{O}_{\text {(ads) }} \leftrightarrow \mathrm{Org}_{\text {(ads) }}+\mathrm{H}_{2} \mathrm{O}_{\text {(sol) }}
$$

where $\mathrm{Org}_{\text {(sol) }}$ and $\mathrm{Org}_{\text {(ads) }}$ are the organic compound which dissolved in the aqueous solution and adsorbed onto the metallic surface, respectively, $\mathrm{H}_{2} \mathrm{O}$ is the water molecule adsorbed on the metallic surface and $\mathrm{x}$ is the size ratio representing the number of water molecules replaced by one organic adsorbate.

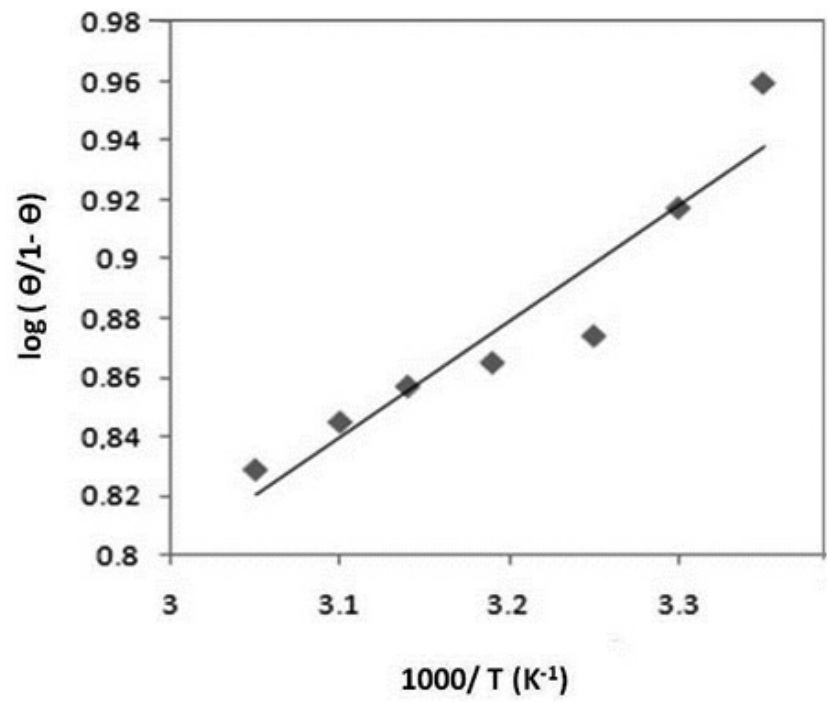

Fig. 8. $\log (\theta / 1-\theta)$ vs $1000 / T$ for adsorption BIS-IMIN molecule.

Adsorption of organic compounds on the metal surface causes a decrease in randomness, hence in $\Delta S_{\text {ads }}$. The desorption of water molecules causes a increase in disorderness. Thermodynamic parameters are total of the adsorption of organic compounds and desorption of water molecules. If the positive sign $\Delta S_{\text {ads }}$ is obtained, it shows that the increase of solvent entropy [30]. In the other way, disorderness increases with the desorption of water molecules from the metal surface by one organic compound [6].

\subsection{FTIR Analysis}

The Schiff base reaction of 4-(4-aminophenylthio) benzenamine with 2-hydroxy-5-methoxybenzaldehyde in a 1:2 ratio which was mixed. This newly synthesized Schiff base compound. The main IR bands (Fig. 9) Ar-H at $3070 \mathrm{~cm}^{-1}, \mathrm{CH}=\mathrm{N}$ at $1613 \mathrm{~cm}^{-1}$ was observed.

${ }^{1} \mathrm{H}-\mathrm{NMR}$ (Fig. 10) and ${ }^{13} \mathrm{C}-\mathrm{NMR}$ (Fig. 11) data of Schiff base compound in deutero form of DMSO were collected. The integration was observed which was in accordance with, 1:2 formulations proposed. $-\mathrm{OCH}_{3}$ was observed at $3.75 \mathrm{ppm}$, the multiply peaks observed at 6.91 and $7.25 \mathrm{ppm}$ were assigned to aromatic ring protons respectively. The singlet at $8.94 \mathrm{ppm}$ was assigned to $\mathrm{CH}=\mathrm{N}$ protons, and the singlet at $12.27 \mathrm{ppm}$ was assigned $\mathrm{Ar}-\mathrm{OH}$ proton. The ${ }^{13} \mathrm{C}$-NMR spectra data of compound was also in accord with the proposed structure. The elemental analyses was compatibility to proposed structural.

IR $\left(\right.$ ATR cm $\left.\mathrm{cm}^{-1}\right): 3070(\mathrm{Ar}-\mathrm{H}), 1613(\mathrm{CH}=\mathrm{N}) ;{ }^{1} \mathrm{H}$ NMR $(\mathrm{d}-\mathrm{DMSO}, \mathrm{ppm})$ : $3.75\left(\mathrm{~s}, 3 \mathrm{H}, \mathrm{OCH}_{3}\right), 6.91(\mathrm{~d}, 2 \mathrm{H}, \mathrm{Ar}-\underline{\mathrm{H}}), 7.05$ (dd, $\left.1 \mathrm{H}, \mathrm{Ar}-\underline{\mathrm{H}}\right), 7.25$ (d, $1 \mathrm{H}, \mathrm{Ar}-$ $\underline{\mathrm{H}}), 8.94(\mathrm{~s}, 1 \mathrm{H}, \overline{\mathrm{CH}}=\mathrm{N}), 12.27(\mathrm{~s}, 1 \mathrm{H}, \mathrm{Ar}-\mathrm{OH}) ;{ }^{13} \mathrm{C}$ NMR $\left(\mathrm{d}_{6}-\mathrm{DMSO}, \mathrm{ppm}\right): 56$, $115,117,119,121,123,127,132,133,136,148,152,154,163$.

\subsection{SEM Analysis}

SEM images and the EDS analysis obtained from SS surface after specimens immersion in $0.5 \mathrm{M} \mathrm{HCl}$ solutions for 2 days in the absence and presence of $5.0 \times 10^{-3} \mathrm{M}$ of BIS-IMIN.

After 2 days immersion in $0.5 \mathrm{M} \mathrm{HCl}$ without the BIS-IMIN, the morphology of SS is shown in Fig. 11a, which is typical corrosive attack on a surface with diverse features and rugosity apparent. The accompanying EDX analysis, shown in Fig. $11 \mathrm{c}$, naturally revealed the presence of the main $\mathrm{Cl}$ peak, apart from the peaks corresponding to Fe. Fig. $11 \mathrm{~b}$ is the morphology that resulted after testing in $0.5 \mathrm{M} \mathrm{HCl}$ in the presence of the $5.0 \times 10^{-3} \mathrm{M}$ inhibitor. Although the resulting morphology apparently looks similar to the previous one, the main difference is given by the EDX spectrum, see Fig. 11d, which bears very small $\mathrm{Cl}$ peak, thus suggesting that the BIS-IMIN molecule has adsorbed on steel surface, which is responsible for the inhibition of corrosion. There is much less corrosion product at the electrode surface.

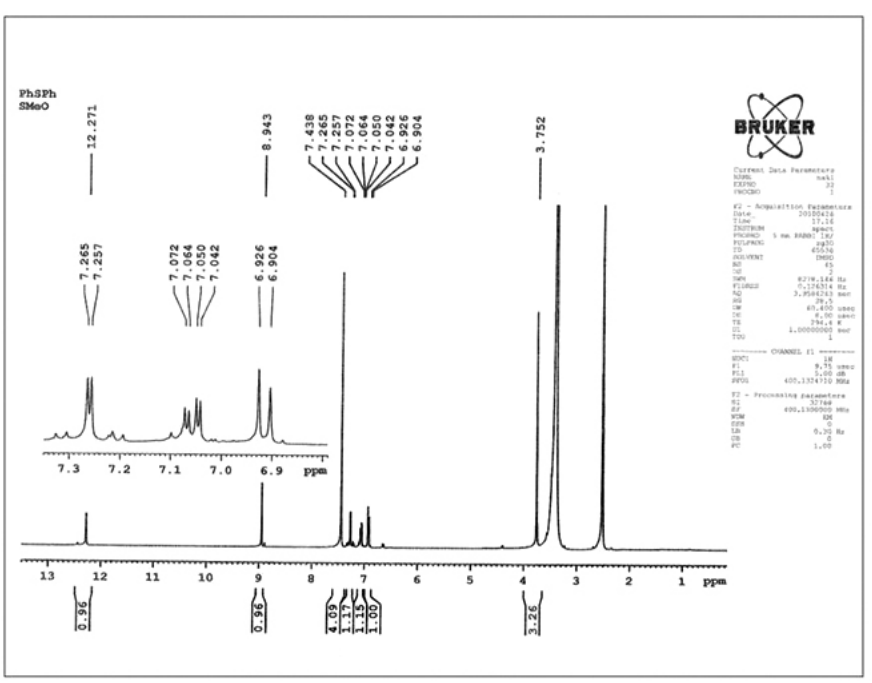

Fig. 9. ${ }^{1} \mathrm{H}$ NMR spectrum of BIS-IMIN molecule.

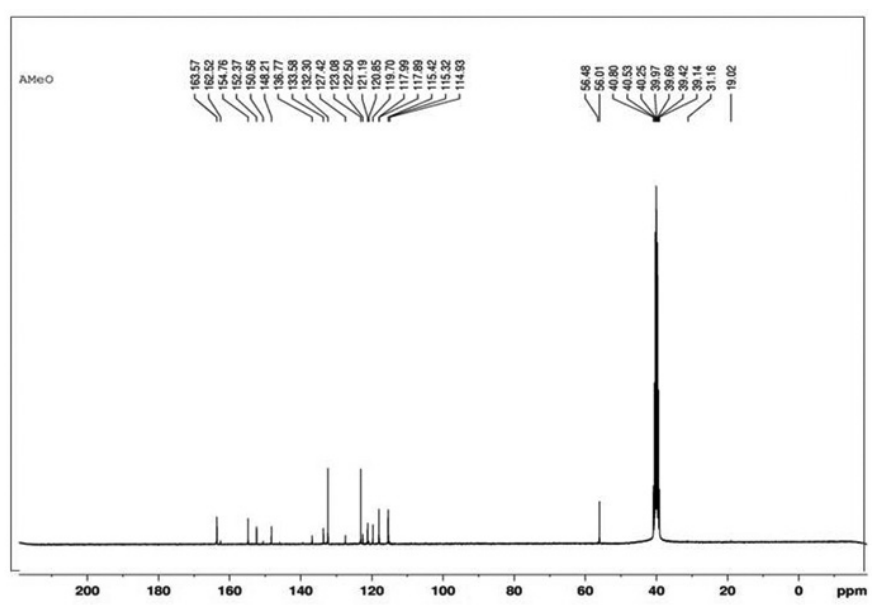

Fig.10. ${ }^{13} \mathrm{C}$ NMR spectrum of BIS-IMIN molecule.

\section{CONCLUSION}

In the present work, electrochemical impedance spectroscopy, potentiodynamic polarization methods were used to study the protection performance of BIS-IMIN to inhibit the corrosion of mild steel in $0.5 \mathrm{M} \mathrm{HCl}$ solutions at $25^{\circ} \mathrm{C}$.

The following are the main conclusions of this study:

This molecule reduced significantly the corrosion of mild steel in $0.5 \mathrm{M}$ $\mathrm{HCl}$. BIS-IMIN is suitable inhibitor for $\mathrm{SS}$ in $0.5 \mathrm{M} \mathrm{HCl}$ solution and its efficiency increase with increasing concentration values. EIS plots indicated that the addition of inhibitors increases the charge-transfer resistance of the corrosion process. Polarization curves demonstrated that this molecule was of mixed-type inhibitor for SS corrosion in these acid solutions. Corrosion current density is increased by increasing the temperature, but the rate of its increase is lower at the presence of BIS-IMIN. This schiff base is adsorptive inhibitor and its adsorption obeys the Langmuir's adsorption isotherm. Thermodynamic adsorption parameters such as $\Delta G, \Delta H$ and $\Delta S$, show that BIS-IMIN are adsorbed by a spontaneous exothermic process.

\section{ACKNOWLEDGMENTS}

The authors are grateful to Hitit University BAP unit for financial support to the project number of FEF03.11.006. 
(a)
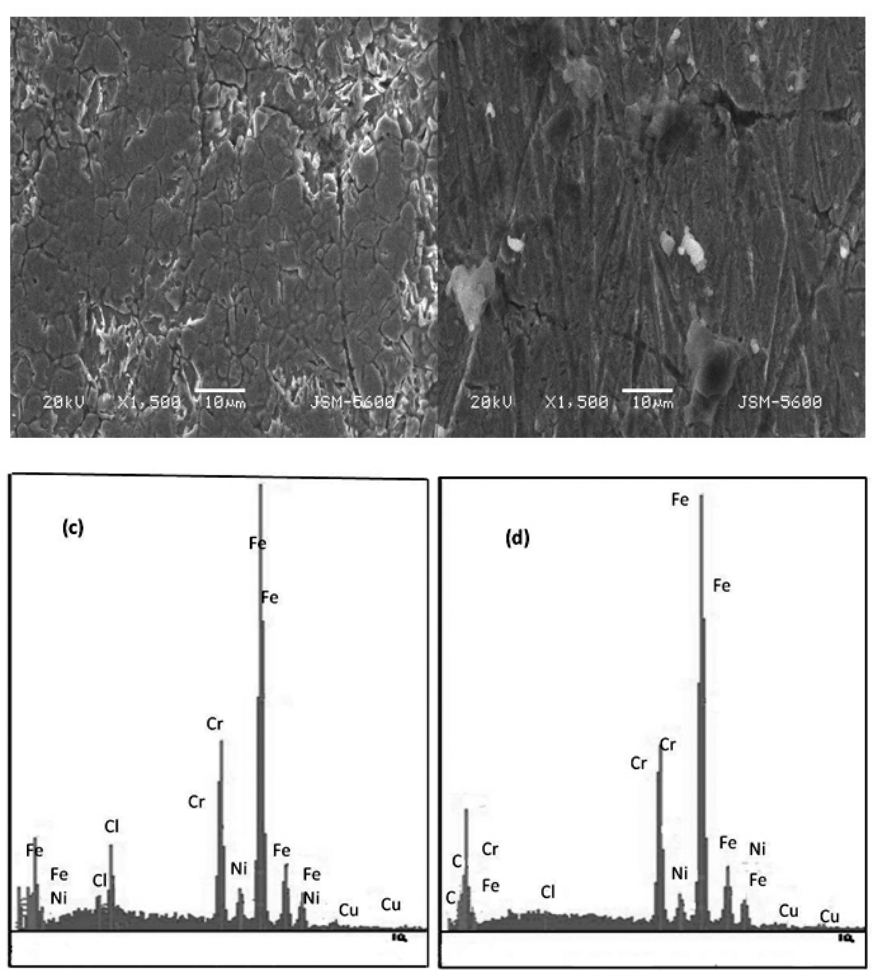

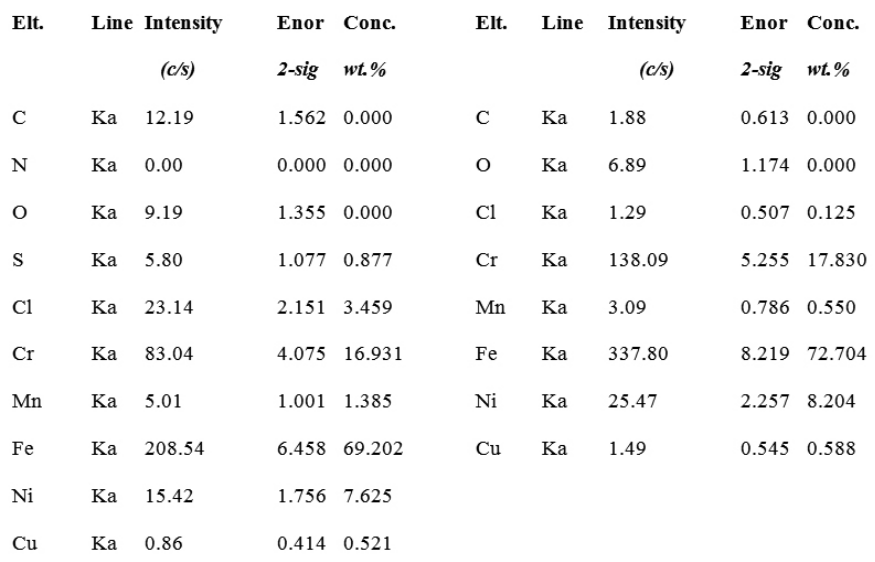

Fig. 11. The SEM images and their corresponding EDX analysis of the stainless steel surface: (a) and (b) belong to the steel corroded in $0.5 \mathrm{M} \mathrm{HCl}$ without inhibitor, (c) and (d) correspond to the working steel electrode exposed to the acid in the presence of the BIS-IMIN inhibiting molecule.

\section{REFERENCES}

1.- M. A. Migahed, M. Abd-El-Raouf, A. M. Al-Sabagh, Electrochim Acta $50,4683,(2005)$

2.- A. V. Shanbhag, T. V. Venkatesha, R. A. Prabhu, J Appl Electrochem 38, $279,(2008)$

3.- E. Machnikova, K. H. Whitmire, N. Hackerman, Electrochim Acta 53, 6024, (2008)

4.- $\quad$ K. F. Khaled, Electrochim Acta 53, 3484, (2008)

5.- M. Sahin, G. Gece, F. Karci, J Appl Electrochem 38, 809, (2008)

6.- E. Naderi, A. H. Jafari, M. Ehteshamzadeh, M. G. Hosseini, Mater Chem Phys 115, 852, (2009)

7.- $\quad$ F. Bentiss, M. Lagrenee, M. Traisnel, J. C. Hornez, Corros Sci 417, 89, (1999)

8.- M. E. Achouri, S. Kertit, H. M. Gouttaya, B. Nciri, Y. Bensouda, L. Perez, M. R. Infante, K. Elkacemi, Prog Org Coat 43, 267, (2001)

9.- A. Chetouani, A. Aouniti, B. Hammouti, N. Benchat, T. Benhadda, S. Kertit, Corros Sci 45, 1675, (2003)
10.- R. Solmaz, G. Kardas, M. Culha, B. Yazici, M. Erbil, Electrochim Acta 53, 5941, (2008)

11.- T. Tsuru, S. Haruyama, B. Gijutsu, J Jpn Soc Corros Eng 27, 573, (1978)

12.- L. Elkadi, B. Mernari, M. Traisnel, F. Bentiss, M. Lagrenee, Corros Sci $42,703,(2000)$

13.- F. Bentiss, M. Lebrini, M. Lagrenee, Corros Sci 47, 2915, (2005)

14.- W. Li, Q. He, C. Pei, B. Hou, Electrochim Acta 52, 6386, (2007)

15.- A. Yurta, A. Balaban, S.U. Kandemir, G. Bereket, B. Erk, Mater Chem Phys $85,420,(2004)$

16.- J. Fang, J. Li, J Mol Struct (Theochem.) 593, 179, (2002)

17.- S. S. Abd El-Rehim, H. H. Hassan, M. A. Amin, Corros Sci 46, 5, (2004)

18.- A. K. Maayta, N. A. F. Al-Rawashdeh, Corros Sci 46, 1129, (2004)

19.- L. Tang, X. Li, L. Li, G. Mu, G. Liu, Mat Chem Phys 97, 301, (2006)

20.- S. Kertit, B. Hammouti, Appl Surf Sci 93, 59, (1996)

21.- G. Moretti, F. Guidi, G. Grion, Corros Sci 46, 387, (2004)

22.- O. K. Abiola, N. C. Oforka, Mater Chem Phys 83, 315, (2004)

23.- A. Popova, M. Christov, S. Raicheva, E. Sokolova Corros Sci 46, 1333 , (2004)

24.- G. Bereket, E. Hur, C. Ogretir, Molecular Struc (Thochem) 578, 79, (2002)

25.- S. Ashry, A. Nemr, S. A. Essawy, S. Ragab, Prog in Org Coat 61, 11, (2008)

26.- E. A.Noor, A. H. Al-Moubaraki, Mater Chem and Phys 110, 145, (2008)

27.- R. Solmaz, G. Kardas, M. Culha, B. Yazici, M. Erbil, Electrochim Acta $53,5941,(2008)$

28.- S. M. A. Hosseini, A. Azimi, Corros Sci 51, 728, (2009)

29.- G. Avci, Colloids and Surfaces A: Physicochem and Eng Aspects 317, $730,(2008)$

30.- M. M. Saleh, Mater Chem Phys 98, 83, (2006) 